\title{
A Comparative Study on Optimal Conductor Selection for Radial Distribution Network using Conventional and Genetic Algorithm Approach
}

\author{
MuraliMohan Thenepalle \\ Assistant Professor, EEE Department, University College of Engineering \\ JNTU Kakinada, AP, 533003, India
}

\begin{abstract}
This paper presents the methodology for the selection of optimal conductors, in radial distribution systems by comparative study of the results obtained by conventional or analytical method and Genetic algorithm method (GA).The objective is to minimize the real and reactive power losses in the system and to maximize the total saving in cost of conducting material while maintaining the acceptable voltage levels. The conductor, which is determined by conventional method will satisfy not only the maximum current carrying capacity and maintain acceptable voltage limits. It is observed that the number of computations is more in conventional method than Genetic Algorithm. The proposed method is tested on 13 bus of Andhra Pradesh southern power Distribution Company limited.
\end{abstract}

\section{Keywords}

Genetic algorithm, real power loss, reactive power loss, distributed load flow.

\section{INTRODUCTION}

In most of the existing distribution systems, the conductors are not selected in a systematic way. Therefore, the capital cost of conducting material and power loss in the feeders is more and also the maximum current carrying capacity and voltage limits are not generally satisfied [1]. Several methods of loss reductions in distribution systems have been reported over years. Control of reactive power in distribution systems with end load and fixed load [2] and varying load [3] have been reported giving generalized equations for calculating peak and energy loss reductions .Other studies have been reported on reconductoring that used uniformly distributed load, a simple line feeder that had no lateral tree, or a simple lateral feeder without branches. All these may not be considered as realistic distribution systems. Genetic Algorithms are proposed for selecting the optimal size of conductor for radial distribution networks. The conductor, which is determined by this method, will not only satisfy the maximum current carrying capacity and maintain the acceptable voltage levels of the radial distribution systems. In addition, it gives the maximum saving in capital cost of conducting material and cost of energy loss [4]. In most of the distribution system planning methods the distribution feeders have been used to be of uniform cross section. Attention was given to the problem of optimal conductor selection as early as 1950's by Funk Houser and Huber. This method however cannot be used in general as it is based on uniform load of distribution for the feeder. In 1982 Ponnavaiko and Rao [5] published a model named as PPR model for optimal conductor grading for radial distribution feeders. Their model is flexible and can handle the variations in the load growth rate, load factor, and cost of energy over the planned period. The PPR model considers the grading problem as optimization problem of minimizing the sum of feeder cost and energy loss cost. In PPR model dynamic programming is used to obtain the solution to the optimization problem. However a major draw back of this method is that it cannot handle the radial distribution feeders with lateral branches. In 1988 Tram and Wall [6] have developed a practical computer algorithm for optimal conductor selection for radial distribution feeders. They have explored the possibilities of using voltage regulator instead of reconductoring of the feeder segment to resolve the voltage problem.

\section{PROBLEM FORMULATION}

Consider a line connected between two nodes as shown in the figure 1 .

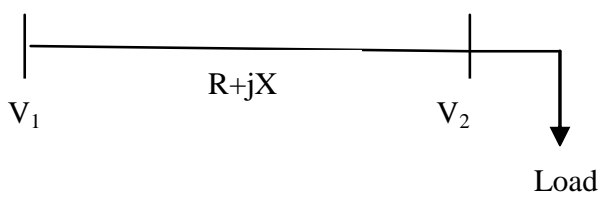

Fig 1: Line connected between two nodes

$\mathrm{V}_{1}$ and $\mathrm{V}_{2}$ are the voltages magnitudes of the two nodes 1 and 2 . Let the current flowing through it be I.

The substation voltage (at sending end) is assumed as $1+\mathrm{j} 0$ p.u.

Let the power factor angle of load $\mathrm{P} 2+\mathrm{jQ} 2$ be $\theta 2$

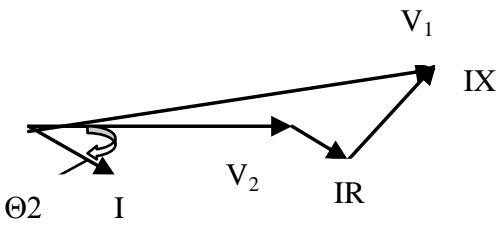

Fig 2: Phasor diagram for figure 1

$$
V_{2}^{4}+2 V_{2}^{2}\left(P_{2} \mathrm{R}+Q_{2} X-V_{1}^{2} / 2\right)+\left(P_{2}^{2}+Q_{2}^{2}\right)\left(R_{2}^{2}+X_{2}^{2}\right)=0
$$

From the two solutions for $\mathrm{V}_{2}$ only positive root of quadratic equation gives a realistic value. 


$$
\begin{aligned}
V_{2}= & \left\{\left[\left(P_{2} R+Q_{2} X+0.5 V_{12}\right)-\left(P_{2}^{2}+Q_{2}^{2}\right)\left(R_{2}^{2}+X_{2}^{2}\right)\right]^{1 / 2}\right. \\
& \left.-\left(P_{2} R+Q_{2} X+0.5 V_{1}^{2}\right)\right\}^{1 / 2}
\end{aligned}
$$

This is straightforward solution and doesn't depend on the phase angle, which simplifies the formulation of the problem [7]-[10]. In distribution system the voltage angle is not so important because the variation of voltage angle from the substation to tail end of distribution feeder is only few degrees. However, if complex power flows in lines are required phase angles are to be considered.

The equation ( 2) can be written in general form as

$$
V_{2}=(B[j]-A[j])^{1 / 2}
$$

Where

$$
\begin{aligned}
& \text { Subscript ' } 2 \text { ' is the receiving end of jth branch. } \\
& \text { Subscript ' } 1 \text { ' is the sending end of jth branch. } \\
& A[j]=P_{2} R[j]+Q_{2} X[j]-0.5 V_{1}^{2} \\
& B[j]=\left[A[j]^{2}-\left(P_{2}^{2}+Q_{2}^{2}\right)\left(R[j]^{2}+X[j]^{2}\right)\right]^{1 / 2}
\end{aligned}
$$

Where $\mathrm{P}_{2}$ and $\mathrm{Q}_{2}$ are total real and reactive power load feed through node 2 after calculating the effective loads at all nodes, the voltages can be calculated using eqns (3), (4) and (5). Let Ploss[j] and Qloss[j] be the real and reactive power loss of branch ' $\mathrm{j}$ ', then the initial estimates of loads are taken as the loads are taken as the effective loads at all nodes and then losses are calculated using the equations.

$$
\begin{aligned}
& \text { Ploss [j] }=\mathrm{R}[\mathrm{j}]\left(P_{2}^{2}+Q_{2}^{2}\right) / V_{2}^{2} \\
& \text { Qloss [j] }=\mathrm{X}[\mathrm{j}]\left(P_{2}^{2}+Q_{2}^{2}\right) / V_{2}^{2}
\end{aligned}
$$

In this method phase angles can also be calculated along with the voltage magnitudes at the end of convergence.

$$
\begin{aligned}
& \mathrm{I}_{1}=\left(\mathrm{V}_{1} \angle \delta_{1} \mathrm{~V}_{2} \angle \delta_{2}\right) / \mid \mathrm{Z} / \theta \\
& \text { Peff }_{2}+\operatorname{Qeff}_{2}=\mathrm{V}_{2} \angle \delta_{2} \mathrm{I} \\
& \text { Peff }_{2}+\text { Qeff }_{2}=\mathrm{V}_{2} \angle \delta_{2}\left(\mathrm{~V}_{1} \angle-\delta_{1}-\mathrm{V}_{2} \angle-\delta_{2}\right) /|\mathrm{Z}| \angle-\theta
\end{aligned}
$$

$\operatorname{Cos}\left(\delta_{21}+\theta\right)=\left(|\mathrm{Z}| /\left(\mathrm{V}_{1} \mathrm{~V}_{2}\right)\right)\left[\mathrm{P}_{\mathrm{eff} 2}+\left(\mathrm{V}_{2} / \mathrm{V}_{1}\right) \cos (\theta) /|\mathrm{Z}|\right.$ the above equation gives

$$
\begin{aligned}
& x=\cos ^{-1}(y) \\
& \delta_{2}=x+\delta_{1}-\theta
\end{aligned}
$$

\section{LOAD FLOW STUDY}

Generally distribution networks are radial and their R/X ratio is very high. Because of this distribution networks are ill conditioned and conventional Newton raphson and fast decoupled load flow methods are inefficient at solving networks [11]. Baran and wu obtained the load flow solution in a distribution system by the iterative solution of three fundamental equations representing the real power, reactive power and voltage magnitude. A special feature of Vector decoupled load flow (VDLF) method illustrated in this work is that all voltage terms are eliminated from the equations for solving the load flows there by simplifying equations for iterative solution. Another advantage of VDLF method is that it requires less computer memory. The algorithm for load flow study is given below.

Step1: Read the system line data and bus data

a) System data: no of buses, no of lines, reference bus or slack bus

b) Line data: from bus, to bus, line resistance, line reactance

c) Bus data: Bus no, pld, qld.

d) Read itmax, epsilon, kvab, kv and initial voltages at all buses.

Step2: Form Ybus identify ie, sending end node (is), receiving end node (ir), xq and $\mathrm{x} 1$ vectors.

Step3: Calculate effective load at each bus starting from the last bus

$$
\begin{aligned}
& \text { Peffp }=\text { Pp+ sum of all loads beyond the node } \mathrm{P} . \\
& \text { Qeffp }=\mathrm{Qp}+\text { sum of all loads beyond the node } \mathrm{p} .
\end{aligned}
$$

step4: Initialize sum of active power loss plss $=0$, sum of reactive power loss qlss $=0$, previous iteration active power loss $\mathrm{pl}=0$, reactive power loss $\mathrm{q} \mathrm{l}=0$.

Step5: Start iteration count it=1

Step6: Initialize total active power loss tpls[i] $=0$, total reactive power loss tqls $[\mathrm{i}]=0$ for $\mathrm{i}=1$ to $\mathrm{n}$. (tpls[i] = total active power loss, tqls[i] = total reactive power loss)

step7: Assign plss=pl, qlss=ql, $\mathrm{pl}=\mathrm{ql}=0$.

Step8: If iteration it=1 go to step 10 else go to step 9

Step9: Find the effective losses at each bus

$$
\begin{aligned}
& \text { for } \mathrm{i}=\mathrm{n} \text { to } 1 \\
& \text { for } \mathrm{j}=\mathrm{is}[\mathrm{i}] \text { to } \operatorname{ir}[\mathrm{i}] \\
& \mathrm{q}=\mathrm{xq}[\mathrm{j}], \mathrm{k}=\mathrm{xl}[\mathrm{j}] \\
& \text { TPLs }[\mathrm{i}]=\mathrm{TPLs}[\mathrm{i}]+\mathrm{TPLs}[\mathrm{q}]+\operatorname{ploss}[\mathrm{k}] \\
& \text { TQLs}[\mathrm{i}]=\mathrm{TQLs}[\mathrm{i}]+\text { TQLs}[\mathrm{q}]+\mathrm{qloss}[\mathrm{k}] \\
& \text { Where ploss[k] = active power loss line } \\
& \text { qloss[k] = reactive power loss of kth line }
\end{aligned}
$$

step10: Calculate load at each bus with losses

Active power $\mathrm{P}[\mathrm{i}]=$ Peffld $[\mathrm{i}]+\mathrm{TPLs}[\mathrm{i}]$.

Reactive power Q[i] = Qeffld[i] + TQLs[i].

Step11: for bus no $\mathrm{i}=2$ to $\mathrm{n}$

$$
\begin{aligned}
& \text { for } \mathrm{j}=\mathrm{is}[\mathrm{i}], \mathrm{q}=\mathrm{xq}[\mathrm{j}], \mathrm{k}=\mathrm{xl}[\mathrm{j}] \\
& \mathrm{A}=(\mathrm{P}[\mathrm{i}] * \mathrm{r}[\mathrm{k}]+\mathrm{Q}[\mathrm{i}] * \mathrm{x}[\mathrm{k}])-(0.5 * \mathrm{~V}[\mathrm{q}] * \mathrm{~V}[\mathrm{q}]) \\
& \mathrm{B}=\operatorname{sqrt}(\mathrm{A} * \mathrm{~A}-(\mathrm{r}[\mathrm{k}] * \mathrm{r}[\mathrm{k}]+\mathrm{x}[\mathrm{k}] * \mathrm{x}[\mathrm{k}]) *(\mathrm{P}[\mathrm{i}] * \mathrm{P}[\mathrm{i}]+\mathrm{Q}[\mathrm{i}] * \mathrm{Q}[\mathrm{i}])) \\
& \mathrm{V}[\mathrm{i}]=\operatorname{sqrt}(\mathrm{B}-\mathrm{A}) \\
& \operatorname{ploss}[\mathrm{k}]=\mathrm{r}[\mathrm{k}] *(\mathrm{P}[\mathrm{i}] * \mathrm{P}[\mathrm{i}]+\mathrm{Q}[\mathrm{i}] * \mathrm{Q}[\mathrm{i}]) / \mathrm{V}[\mathrm{i}] * \mathrm{~V}[\mathrm{i}] \\
& \text { qloss }[\mathrm{k}]=\mathrm{x}[\mathrm{k}] *(\mathrm{P}[\mathrm{i}] * \mathrm{P}[\mathrm{i}]+\mathrm{Q}[\mathrm{i}] * \mathrm{Q}[\mathrm{i}]) / \mathrm{V}[\mathrm{i}] * \mathrm{~V}[\mathrm{i}] \\
& \mathrm{pls}=\mathrm{pls}+\mathrm{ploss}[\mathrm{k}] \\
& \mathrm{qls}=\mathrm{qls}+\mathrm{qloss}[\mathrm{k}] \\
& \text { step12: } \quad \Delta \text { pls }=\text { plss-pls } ; \text { qloss }=\text { qlss-qls } \\
& \text { set } \mathrm{pls}[\mathrm{i}]=\mathrm{qls}[\mathrm{i}]=0 \text { for } 1 \text { to } \ln \\
& \text { step13: } \quad \text { if } \Delta \mathrm{pls}<\text { tol and } \Delta \mathrm{q} l \mathrm{~s}<\text { tol go to step } 16 \\
& \text { else go to step } 5
\end{aligned}
$$


step14: If iteration > itmax go to step 15

step15: Problem is not converged in itmax iterations

step16: Problem is converged in it iterations. Calculate phase angle at each bus using equation (10). Print voltages and phase angles at each bus and total active power loss.

\section{OPTIMUM CONDUCTOR GRADING}

The fundamental objective of the optimal conductor grading is to minimize the objective function which consists of capital cost investment and energy losses. This can be obtained by using two methods such as Analytical method and genetic algorithm method.

\subsection{Analytical Method}

The conductor, which is determined by this method, will satisfy not only the maximum current carrying capacity and maintain acceptable voltage levels but also, it gives the maximum saving in capital cost of conductor and cost of energy loss in radial distribution system. In a radial distribution system, the optimal choice of the size of conductor in each branch of the system, which minimizes the sum of depreciation on capital investment and cost of energy losses, is important. The problem of choice of the optimal size of conductor for each feeder segment is presented as an optimization problem using branch wise minimization technique [12]-[13]. In normal practice, the conductors used for radial distribution feeders are uniform in cross-section. However, the load at the sub-station level is high and it reduces as one proceeds on to the tail end of the feeder. This indicates that the use of a higher size conductor which is capable of supplying load to source point is not necessarily at tail end point. Similarly use of different conductor cross section for intermediate sections will lead to a minimum both in respect of capital investment cost and line loss point of view. The use of a large number of conductors of different cross sections will result in increased cost of the inventory. A judicious choice can, however be made in the selection of number of size of conductor cross-section for considering the optimal design. In this paper, four different types of conductors viz. Squirrel, Weasel, Rabbit and Ferret are used for optimal conductor selection.

\section{Objective Function}

The objective is to select optimal size of the conductor in each branch of the system, which minimizes the sum of depreciation on capital investment and cost of energy losses. The objective function for optimal selection of conductor for branch $\mathrm{jj}$ with $\mathrm{k}$ type conductor is

$\operatorname{MinF}(\mathrm{jj}, \mathrm{k})=\mathrm{CL}(\mathrm{jj}, \mathrm{k})+\mathrm{CC}(\mathrm{jj}, \mathrm{k})$

i) CL is the cost of energy losses, the annual cost for the loss in branch jj with $\mathrm{k}$ type conductor is

$\mathrm{CL}(\mathrm{jj}, \mathrm{k})=$ Peakloss $(\mathrm{jj}, \mathrm{k})[\mathrm{cpl}+\mathrm{cel} * \mathrm{fll} * 8760]$

where $\quad \mathrm{cpl}=$ annual demand cost of power loss $(\mathrm{Rs} / \mathrm{KW})$

cel $=$ annual cost of energy loss $(\mathrm{Rs} / \mathrm{KWh})$

fll $=$ loss factor

Peakloss $=$ real power loss of branch jj under peak

load conditions with $\mathrm{k}$ type conductor. ii) $\mathrm{CC}$ is the depreciation on capital investment, the annual capital cost for branch $\mathrm{jj}$ with $\mathrm{k}$ type conductor is given by

$$
\mathrm{CC}(\mathrm{jj}, \mathrm{k})=\mathrm{fid}^{*}[\operatorname{cost}(\mathrm{k}) * \operatorname{len}(\mathrm{jj})]
$$

where fid $=$ interest and depreciation factor.

$$
\text { cost }(\mathrm{k})=\text { cost of } \mathrm{k} \text { type conductor }(\mathrm{Rs} / \mathrm{KM})
$$$$
\text { len }(\mathrm{jj})=\text { length of branch } \mathrm{jj}(\mathrm{KM})
$$

Loss factor is defined as ratio of energy loss in the system during a given time period to the energy loss that could result if the system peak loss persist throughout that period. In British experience, loss factor is expressed in terms of the load factor.

$$
\mathrm{Lsf}=0.2 \mathrm{Lf}+0.8 \mathrm{Lf}^{2}
$$

Once the loss factor is found, one can determine the capital cost of energy losses. This cost equals 8760 times the product of the loss factor, distribution system peak load losses and energy cost. Annual demand cost of power loss (cpl) represents the marginal Cost, which is the additional cost that is incurred in generating one more unit or conversely the cost that is saved if one unit is less generated $(1 \mathrm{KW}$ or $1 \mathrm{KWH})$. Depreciation enables the correct cost for economic use of assets to be charged in a balance sheet before the profit is cleared. The practical system data for annual cost of power and energy losses are given as follows.

Annual demand cost of power loss $(\mathrm{cpl})=1000(\mathrm{Rs} / \mathrm{KW})$

Annual cost of energy loss $(\mathrm{cel})=0.5(\mathrm{Rs} / \mathrm{KWh})$

Loss factor $(\mathrm{fll})=0.208$

Interest and depreciation factor (fid) $=0.1$

Constraint equations

i) Feeder voltage: the feeder voltage at every node in the feeder must be above the acceptable voltage level, i.e.

$$
|\mathrm{V}(\mathrm{m} 2 . \mathrm{k})|>\mathrm{Vmin} \quad \text { for } \mathrm{m}_{2}=2,3,-----------n
$$

ii) Maximum current carrying capacity: current flowing through branch $\mathrm{jj}$ with $\mathrm{k}$ type conductor should be less than the maximum current carrying capacity of $\mathrm{k}$ type conductor, Imax (k), i.e.

$$
\mathrm{I}(\mathrm{jj}, \mathrm{k}) \mid<\mathrm{I} \max (\mathrm{k}) \text { for all branches1, 2, ---------n line }
$$

\subsection{Algorithm for Analytical method}

The detailed Algorithm to determine economic size of the conductor is given below

Step1: Read the conductor data along with system load and line data

a. Read objective function constants (cpl, cel, fll, fid).

b. Read Vmin, kvab, KVb.

Step2: Set the conductor count ' $k$ ' $=1$.

Step3: Run the VDLF load flow method.

Step4: Calculate current and real power losses under peak load condition of branch with $\mathrm{k}$ type conductor.

Step5: Calculate the objective function of branch jj with $\mathrm{k}$ type conductor.

$$
\operatorname{Min} F(j j, k)=C L(j j, k)+C C(j j, k)
$$


Step6: Repeat the procedure from step no. 3 for all conductors. Step7: Arrange the objective function values of the $n$ different types of conductors for all branches in ascending order.

Step8: Set the branch count ' $\mathrm{jj}$ ' $=1$.

Step9: Select minimum cost type of conductor for branch $\mathrm{jj}$.

Step10: Check for voltage \& current constraints i.e.

$$
\begin{aligned}
& V(m 2, k)>V \min \\
& I(j j, k)<\operatorname{Imax}(k) \quad \text { for } m_{2}=2,3 \ldots \ldots \ldots n \\
& j j=1,2 \ldots \ldots \ldots . n
\end{aligned}
$$

If satisfied, print the result of optimal type of conductor for branch $\mathrm{jj}$. else go to step no. 9

Step11: Repeat the procedure from step no 11 for all branches. Step12: Run the load flow for optimally selected conductors.

Step13: Print the voltages, total real power losses, reactive power losses\& the sum of the total cost of conductor and energy losses.

\subsection{Implementation Using Genetic Algorithm}

The detailed algorithm to determine economic size of the conductor is given below [14]-[19].

step1: Read the genetic data along with system load, line and conductor data

a. Read objective function constants (cpl, cel, fll, fid).

b .Read vmin, kvab, kvb.

c. Read the genetic operator values (population size, Pe, Pc, Pm, etc)

Step2: Initialization of population.

Step3: Set the iteration count to '1'.

Step4: Set chromosome count equal to ' 1 '.

Step5: Decode the chromosomes of the population and determine the conductor number from the normalized form.

Step6: Run the VDLF load flow method.

Step7: Calculate the objective function.

Step8: Calculate the fitness value of the chromosome, using the formula $\mathrm{Fit}[\mathrm{w}]=1.0 /\left(1+0.005^{*} \mathrm{obj}[\mathrm{w}]\right)$;

Where w is chromosome count.

Step9: Repeat the procedure from step no.5 until chromosome count greater than population size.

Step10: Sort the chromosomes and all their related data in the ascending order of fitness.

Step11: Calculate the error (Fit [1]-Fit [PS]).

Step12: Check if the error is less than $0.0001 \&$ check whether voltage and constraints are satisfied, if yes go to 17 .

Step13: Now copy the Pe \% (ei) chromosomes of old population to new population starting from the best ones from the top.

Step14: Now perform crossover and mutation operators respectively for generating remaining chromosomes.

Step15: Now, replace old population with new population.

Step16: Increment iteration count. If iteration count less than max. Count, go to 4. else go to 18 .
Step17: Print the message "problem is converged". Print the total real power loss reactive power loss, converged voltages.

step18: Print the message "maximum number of iterations has reached, yet the problem has not converged".

\section{CASE STUDY}

In this study a 13 bus system is analyzed. Its single line diagram is given below.

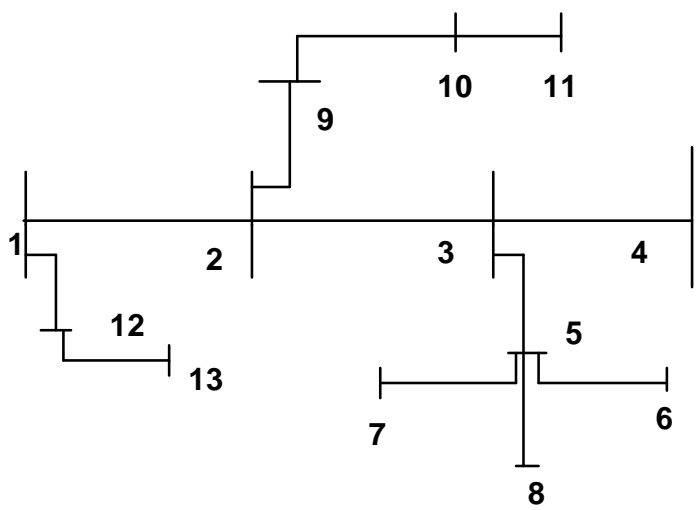

Fig 3. $11 \mathrm{Kv}$ route map of Bonagiripalli feeder

The proposed method is applied to practical radial distribution system as shown in figure 3 .The line and load data for 13 buses practical radial distribution system is given in tables 1 and 2 for the optimization of branch conductor, four types of different conductors are used. The electrical properties of conductors are given in table 3. limit of the minimum voltage is taken as $\mathrm{V}_{\text {min }}=$ $0.90 \mathrm{pu}$. A radial distribution system has several branches. When these branches are reconductored, it alters the flow of power and it changes the resulting power losses and voltage profile. The reconductored branches required capital investment. The proposed algorithm is to select the best conductor type for each branch of the system, such that the resulting radial distribution system requires the least reconductoring costs, yields the minimum power losses and best voltage profile.

\subsection{System data}

The details of 13 bus system data is given below.

Name of the feeder: Bonagiripalli

Name of the substation to which it is connected: Rajampeta

$\begin{array}{lcc}\text { No. of buses } & = & 13 \\ \text { No. of lines } & = & 12 \\ \text { Slack bus no. } & = & 01 \\ \text { Tolerance } & = & 0.001 \\ \text { Base KV } & = & 11 \\ \text { Base KVA } & = & 100\end{array}$


Table1. System data for Bonagiripalli feeder

\begin{tabular}{|c|c|c|c|c|c|}
\hline $\begin{array}{l}\dot{\Xi} \\
\stackrel{0}{\Xi}\end{array}$ & 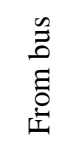 & 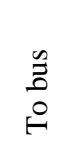 & 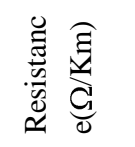 & 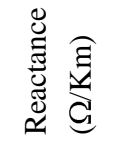 & 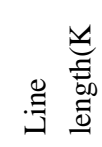 \\
\hline 1 & 1 & 2 & 0.005862 & 0.01596 & 0.4 \\
\hline 2 & 2 & 3 & 0.35172 & 0.09576 & 0.3 \\
\hline 3 & 3 & 4 & 0.2931 & 0.0798 & 0.2 \\
\hline 4 & 3 & 5 & 0.05865 & 0.01595 & 0.4 \\
\hline 5 & 5 & 6 & 0.041034 & 0.11172 & 0.12 \\
\hline 6 & 5 & 7 & 0.11724 & 0.3192 & 0.18 \\
\hline 7 & 5 & 8 & 0.05865 & 0.01596 & 0.10 \\
\hline 8 & 2 & 9 & 0.23448 & 0.06384 & 0.12 \\
\hline 9 & 9 & 10 & 0.05865 & 0.01596 & 0.06 \\
\hline 10 & 10 & 11 & 0.05865 & 0.01596 & 0.05 \\
\hline 11 & 1 & 12 & 0.23448 & 0.06384 & 0.02 \\
\hline 12 & 12 & 13 & 0.17586 & 0.04788 & 0.03 \\
\hline
\end{tabular}

Table 2. Load data for Bonagiripalli feeder

\begin{tabular}{|l|l|l|}
\hline Bus no. & $\begin{array}{l}\text { Real } \\
\text { power(Kw) }\end{array}$ & $\begin{array}{l}\text { Reactive } \\
\text { power(Kvar) }\end{array}$ \\
\hline 1 & 0 & 0 \\
\hline 2 & 2.0 & 1.154 \\
\hline 3 & 4.0 & 2.309 \\
\hline 4 & 3.0 & 1.732 \\
\hline 5 & 6.0 & 3.464 \\
\hline 6 & 0.5 & 0.288 \\
\hline 7 & 0.5 & 0.288 \\
\hline 8 & 1.0 & 0.577 \\
\hline 9 & 5.595 & 3.220 \\
\hline 10 & 1.0 & 0.577 \\
\hline 11 & 9.325 & 5.3805 \\
\hline 12 & 5.739 & 3.313 \\
\hline 13 & 0 & 0 \\
\hline
\end{tabular}

Table3. Electrical characteristics of $11 \mathrm{KV}$ conductors

\begin{tabular}{|c|c|c|c|c|c|}
\hline S. No & 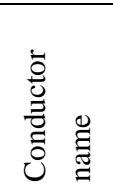 & 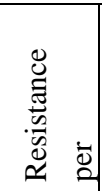 & 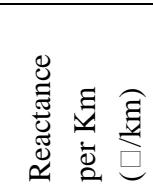 & 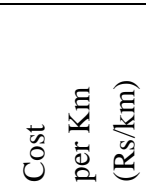 & $\begin{array}{l}\prec \\
\Xi \\
\Xi \\
ٌ \\
\Xi\end{array}$ \\
\hline 1 & Squirrel & 1.371 & 0.39 & 11695 & 107 \\
\hline 2 & Weasel & 0.911 & 0.38 & 11695 & 139 \\
\hline 3 & Rabbit & 0.514 & 0.37 & 17752 & 193 \\
\hline 4 & Ferret & 0.73 & 0.376 & 11700 & 130 \\
\hline
\end{tabular}

Table 4. System data for 13 bus system

\begin{tabular}{|l|l|l|l|l|}
\hline $\begin{array}{l}\text { Line } \\
\text { no. }\end{array}$ & $\begin{array}{l}\text { From } \\
\text { bus }\end{array}$ & To bus & $\begin{array}{l}\text { Resistance } \\
\mathrm{r}[\mathrm{i}] \\
(\mathrm{pu})\end{array}$ & $\begin{array}{l}\text { Reactance } \\
\mathrm{x}[\mathrm{i}] \\
\mathrm{(pu})\end{array}$ \\
\hline 1 & 1 & 2 & 0.0001 & 0.0001 \\
\hline 2 & 2 & 3 & 0.0001 & 0.0001 \\
\hline 3 & 3 & 4 & 0 & 0.0001 \\
\hline 4 & 3 & 5 & 0.0001 & 0.0001 \\
\hline 5 & 5 & 6 & 0.0001 & 0 \\
\hline 6 & 5 & 7 & 0.0001 & 0.0001 \\
\hline 7 & 5 & 8 & 0.0001 & 0 \\
\hline 8 & 2 & 9 & 0 & 0 \\
\hline 9 & 9 & 10 & 0 & 0 \\
\hline 10 & 10 & 11 & 0 & 0 \\
\hline 11 & 1 & 12 & 0 & 0 \\
\hline 12 & 12 & 13 & 0 & 0 \\
\hline
\end{tabular}

Table 5. Load data for 13 bus system

\begin{tabular}{|l|l|l|}
\hline Bus no. & Pload $(\mathrm{pu})$ & Qload $(\mathrm{pu})$ \\
\hline 1 & 0 & 0 \\
\hline 2 & 0.02 & 0.0154 \\
\hline 3 & 0.04 & 0.02309 \\
\hline 4 & 0.03 & 0.0173 \\
\hline 5 & 0.06 & 0.3464 \\
\hline 6 & 0.005 & 0.00288 \\
\hline 7 & 0.005 & 0.00288 \\
\hline 8 & 0.01 & 0.0057 \\
\hline 9 & 0.0556 & 0.322 \\
\hline 10 & 0.01 & 0.0577 \\
\hline 11 & 0.09325 & 0.0538 \\
\hline 12 & 0.05739 & 0.0313 \\
\hline 13 & 0.057539 & 0.0313 \\
\hline
\end{tabular}

\section{RESULTS AND DISCUSSION}

\subsection{Results with Analytical method}

Table 9.Losses of conductors for 13 bus system

\begin{tabular}{|l|l|l|l|}
\hline Conductor no. & $\begin{array}{l}\text { Ploss } \\
(\mathrm{pu})\end{array}$ & $\begin{array}{l}\text { Qloss } \\
(\mathrm{pu})\end{array}$ & $\begin{array}{l}\text { No. of } \\
\text { iterations } \\
\text { to } \\
\text { converge }\end{array}$ \\
\hline 1 & 0.90 & 0.25 & 3 \\
\hline 2 & 0.59 & 0.24 & 3 \\
\hline 3 & 0.33 & 0.23 & 3 \\
\hline 4 & 0.472 & 0.243 & 3 \\
\hline
\end{tabular}


Table 10. Optimal conductor selection for each branch of 13 bus system

\begin{tabular}{|c|c|}
\hline Line no. & $\begin{array}{c}\text { Optimal conductor } \\
\text { selected }\end{array}$ \\
\hline 1 & 4 \\
\hline 2 & 4 \\
\hline 3 & 2 \\
\hline 4 & 4 \\
\hline 5 & 2 \\
\hline 6 & 2 \\
\hline 7 & 2 \\
\hline 8 & 4 \\
\hline 9 & 4 \\
\hline 10 & 4 \\
\hline 11 & 4 \\
\hline 12 & 4 \\
\hline
\end{tabular}

Table 11. Converged voltages after the placement of optimal conductors for 13 bus system

\begin{tabular}{|l|l|}
\hline Bus no. & Voltage(p.u) \\
\hline 1 & 1 \\
\hline 2 & 0.9877 \\
\hline 3 & 0.9841 \\
\hline 4 & 0.9836 \\
\hline 5 & 0.9816 \\
\hline 6 & 0.9815 \\
\hline 7 & 0.9815 \\
\hline 8 & 0.9815 \\
\hline 9 & 0.9862 \\
\hline 10 & 0.9857 \\
\hline 11 & 0.9853 \\
\hline 12 & 0.9991 \\
\hline 13 & 0.9875 \\
\hline
\end{tabular}

Table12. Total power losses and cost accounted after the selection of Conductors

\begin{tabular}{|l|l|}
\hline & $\begin{array}{l}\text { After placement } \\
\text { of conductors }\end{array}$ \\
\hline Total real power loss(pu) & 0.0592635 \\
\hline Total reactive power loss(pu) & 0.0305248 \\
\hline $\begin{array}{l}\text { Total cost accounted in selection of } \\
\text { the conductor(Rs) }\end{array}$ & 2429.56 \\
\hline
\end{tabular}

\subsection{Results with GA}

The genetic parameters depending upon different sections are selected as shown below

Population size $=10$

Elitism probability $=0.2$
Crossover probability $=0.7$

Mutation probability $=0.1$

Table 13. Total power losses and cost accounted after the selection of Conductors

\begin{tabular}{|lr|l|}
\hline & & $\begin{array}{l}\text { After placement of } \\
\text { conductors }\end{array}$ \\
\hline $\begin{array}{l}\text { Total real power } \\
\text { loss(p.u) }\end{array}$ & 0.0452264 \\
\hline $\begin{array}{l}\text { Total reactive power } \\
\text { loss(p.u) }\end{array}$ & 0.0291032 \\
\hline $\begin{array}{l}\text { Total cost } \\
\text { accounted(Rs) }\end{array}$ & 2665.86 \\
\hline
\end{tabular}

Table 14.Optimal conductor selection for each branch of 13 bus system

\begin{tabular}{|c|c|}
\hline Line no. & $\begin{array}{c}\text { Optimal } \\
\text { conductor } \\
\text { Selected }\end{array}$ \\
\hline 1 & 3 \\
\hline 2 & 4 \\
\hline 3 & 1 \\
\hline 4 & 4 \\
\hline 5 & 4 \\
\hline 6 & 4 \\
\hline 7 & 4 \\
\hline 8 & 4 \\
\hline 9 & 2 \\
\hline 10 & 4 \\
\hline 11 & 2 \\
\hline 12 & 2 \\
\hline
\end{tabular}

Table 15. Converged voltages after the placement of optimal conductors for 13 Bus system

\begin{tabular}{|l|l|}
\hline Bus no. & Voltages(p.u) \\
\hline 1 & 1 \\
\hline 2 & 0.99907 \\
\hline 3 & 0.998717 \\
\hline 4 & 0.998638 \\
\hline 5 & 0.998467 \\
\hline 6 & 0.998462 \\
\hline 7 & 0.99846 \\
\hline 8 & 0.998459 \\
\hline 9 & 0.998921 \\
\hline 10 & 0.998863 \\
\hline 11 & 0.998826 \\
\hline 12 & 0.999991 \\
\hline 13 & 0.999057 \\
\hline
\end{tabular}




\section{COMPARATIVE STUDY}

Table 16. Comparison of real and reactive power loss between without GA method (CM) and GA for 13 bus system

\begin{tabular}{|l|l|l|}
\hline & $\begin{array}{l}\text { With conductors } \\
\text { selected by } \\
\text { Conventional } \\
\text { method }\end{array}$ & $\begin{array}{l}\text { with } \\
\text { conductors } \\
\text { selected by } \\
\text { (GA) }\end{array}$ \\
\hline $\begin{array}{l}\text { Total real power loss } \\
\text { (p.u) }\end{array}$ & 0.0592635 & 0.0452264 \\
\hline $\begin{array}{l}\text { Total reactive power } \\
\text { loss (p.u) }\end{array}$ & 0.0305248 & 0.0291032 \\
\hline $\begin{array}{l}\text { Total cost accounted in } \\
\text { selection of the } \\
\text { conductor(Rs) }\end{array}$ & 2429.56 & 2665.86 \\
\hline
\end{tabular}

Table 17. Comparison of optimal conductor selection between without GA method (CM) and GA for 13 bus system

\begin{tabular}{|c|c|c|}
\hline$\underset{\stackrel{0}{\leftrightarrows}}{\stackrel{0}{\Xi}}$ & 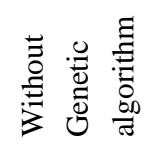 & 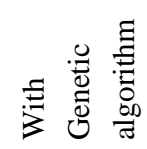 \\
\hline 1 & 4 & 3 \\
\hline 2 & 4 & 4 \\
\hline 3 & 2 & 1 \\
\hline 4 & 4 & 4 \\
\hline 5 & 2 & 4 \\
\hline 6 & 2 & 4 \\
\hline 7 & 2 & 4 \\
\hline 8 & 4 & 4 \\
\hline 9 & 4 & 2 \\
\hline 10 & 4 & 4 \\
\hline 11 & 4 & 2 \\
\hline 12 & 4 & 2 \\
\hline
\end{tabular}

Table 18.Comparison of Converged Voltages between without GA method (CM) and GA for 13 bus system

\begin{tabular}{|l|l|l|}
\hline Bus no. & $\begin{array}{l}\text { Voltages(p.u) } \\
\text { (With out } \\
\text { Genetic } \\
\text { Algorithm) }\end{array}$ & $\begin{array}{l}\text { Voltages(p.u) } \\
\text { (With Genetic } \\
\text { Algorithm) }\end{array}$ \\
\hline 1 & 1 & 1 \\
\hline 2 & 0.9877 & 0.99907 \\
\hline 3 & 0.9841 & 0.998717 \\
\hline 4 & 0.9836 & 0.998638 \\
\hline 5 & 0.9816 & 0.998467 \\
\hline 6 & 0.9815 & 0.998462 \\
\hline
\end{tabular}

\begin{tabular}{|l|l|l|}
\hline 7 & 0.9815 & 0.99846 \\
\hline 8 & 0.9815 & 0.998459 \\
\hline 9 & 0.9862 & 0.998921 \\
\hline 10 & 0.9857 & 0.998863 \\
\hline 11 & 0.9853 & 0.998826 \\
\hline 12 & 0.9991 & 0.999991 \\
\hline 13 & 0.9875 & 0.999057 \\
\hline
\end{tabular}

Table 17 shows that the type of conductor selected for various lines of 13 bus system which is not the same from the two methods. Table 18 gives the voltage profile in per unit values at all the busses which are basically with in the limits and it is observed that the voltage profile given by GA is superior to analytical method. Table 16 gives comparison of total real power loss, total reactive power loss and the cost accounted in selection of the conductors in both the methods. It is observed that though the cost for selection of conductors is more by GA, it gives lesser real power and reactive power loss than conventional method.

\section{CONCLUSIONS}

The method presented for selecting the optimal size of branch conductors maintains the voltages at all buses within the limits, which results in better voltage regulation. The proposed algorithm reduces the total power losses, which minimizes total cost of the system. The proposed algorithm has been tested on distribution network case study of 13 bus system. The results obtained by genetic algorithm and conventional method are compared .It is observed that genetic algorithm yields better results when compared to conventional method. The results obtained by genetic algorithm are quite promising and hence this method is very powerful in finding the solutions for conductor selection problems.

\section{REFERENCES}

[1]. R.N Adams \& M.A Laughton, Optimal planning of power networks using mixed integer programming, Proc. IEE, 121 (2),1974, 139-145.

[2]. M. Ponnavaiko, K.S.P. Rao \& S.S. Venkata, Distribution system planning though a quadrature mixed integer programming approach, IEEE PES Transmission and Distribution Conf., Anaheim, CA, 1986, Paper No. 86T\&D521-9.

[3]. M. Ponnavaiko \& K.S.P Rao, Optimal distribution system planning, IEEE Trans. on Power Apparatus and Systems,100(6), 1981, 2969-2977.

[4]. W.C. Kiran \& R.B. Adler, A distribution system cost model and its application to optimal conductor sizing, IEEE Trans.on Power Apparatus and Systems, 101(2), 1982, 271-275.

[5]. M. Ponnavaiko \& K.S.P. Rao, An approach to optimal distribution system planning through conductor gradation, IEEE Trans. on Power Apparatus and Systems, 101(6), 1982,1735-1742.

[6]. H.N. Tram \& D.L. Wall, Optimal conductor selection in planning radial distribution systems, IEEE Trans. on Power Systems, 3 (1), 1988, 200-206. 
[7]. S. Bhowmik, S.K. Goswami, \& P.K Bhattacherjee, A new

[8]. power distribution planning through reliability evaluation technique, Electrical Power System Research, 54 (3), 2000, 169-179.

[9]. S. Sivanagaraju, N. Srinivasulu, M. Vijayakumar, \& T. Ramana, Optimal conductor selection for radial distribution systems, Electrical Power Systems Research, 63 (2), 2002, 95-103.

[10].R. Ranjan \& D. Das, Novel computer algorithm for solving radial distribution networks, Journal of Electrical Power Components and Systems, 31 (1), 2003, 95-107.

[11].R. Ranjan, B. Venkatesh, \& D. Das, A new algorithm for power distribution systems planning, Journal of Electrical Power Systems

[12].Resea[Baeck, 1998]Baeck, T. A User's Guide to GENEsYs 1.0, Department of Computer Science, University of Dortmund, 1992.
[13].Brooke, A.D., D. Kendrick and A. Meerhaus, A User's Guide, Scientific Press, 1988.

[14].Carroll, D.L., Fortran GA - Genetic Algorithm Driver V1.6.4, Users Guide, 1997.

[15].Goldberg, D.E., Genetic Algorithms in Search, Optimization, and Machine Learning, Addison-Wesley, USA, 1989.

[16].Grefenstette, J.J., GENESIS: a system for using genetic search procedures, Proceedings of the 1984 Conference on Intelligent Systems and Machines, 161-165, 1984.

[17].Holland, J.H., Adaptation in Natural and Artificial Systems, University of Michigan Press, USA, 1975.

[18]. Michalewicz, Z., Genetic Algorithms + Data Structures = Evolution Programs, 3rd ed., Springer, 1996.

[19]. "Electric Distribution Systems", book by Turan Gonen. 